Article

\title{
Bacillus subtilis Type I antitoxin SR6 Promotes Degradation of Toxin yonT mRNA and Is Required to Prevent Toxic yoyJ Overexpression
}

\author{
Celine Reif ${ }^{\dagger}$, Charlotte Löser and Sabine Brantl * \\ Friedrich-Schiller-Universität Jena, Fakultät für Biowissenschaften, Matthias-Schleiden-Institut, \\ AG Bakteriengenetik, Philosophenweg 12, D-07743 Jena, Germany; celine.reif@uni-marburg.de (C.R.); \\ Charlotte.Loeser@uni-jena.de (C.L.) \\ * Correspondence: Sabine.Brantl@uni-jena.de; Tel.: +49-3641-949570 \\ † Current address: Laboratorium für Mikrobiologie, Fachbereich Chemie, Philipps-Universität Marburg, \\ Hans-Meerwein-Straße 4, D-35043 Marburg, Germany.
}

Received: 18 January 2018; Accepted: 4 February 2018; Published: 7 February 2018

\begin{abstract}
T /SR6 is the second type I toxin-antitoxin (TA) system encoded on prophage SP $\beta$ in the $B$. subtilis chromosome. The yonT ORF specifying a 58 aa toxin is transcribed on a polycistronic mRNA under control of the yonT promoter. The antitoxin SR6 is a $100 \mathrm{nt}$ antisense RNA that overlaps yon $T$ at its $3^{\prime}$ end and the downstream gene yoyJ encoding a second, much weaker, toxin at its $5^{\prime}$ end. SR6 displays a half-life of $>60 \mathrm{~min}$, whereas yonT mRNA is less stable with a half-life of $\approx 8 \mathrm{~min}$. SR6 is in significant excess over yonT mRNA except in minimal medium with glucose. It interacts with the $3^{\prime}$ UTR of yonT mRNA, thereby promoting its degradation by RNase III. By contrast, SR6 does not affect the amount or half-life of yoy JRNA. However, in its absence, a yoyJ overexpression plasmid could not be established in Bacillus subtilis suggesting that SR6 inhibits yoyJ translation by directly binding to its ribosome-binding site. While the amounts of both yonT RNA and SR6 were affected by vancomycin, manganese, heat-shock and ethanol stress as well as iron limitation, oxygen stress decreased only the amount of SR6.
\end{abstract}

Keywords: yonT/SR6; sRNA; small regulatory RNA; Bacillus subtilis; type I toxin-antitoxin system; multistress responsive TA system

Key contribution: The yonT/yoyJ/SR6 system is the first type I TA system in which the antitoxin regulates two toxins using two different mechanisms, promotion of RNA degradation and inhibition of translation.

\section{Introduction}

To date, six types of toxin-antitoxin systems are known (reviewed in [1,2]). All these systems comprise two genes, one encoding a stable toxin, the other an unstable antitoxin that neutralizes the toxin action. Whereas in type I and III TA systems, the antitoxin is a small RNA, in type II, IV, V and VI systems toxin and antitoxin are proteins. In the recently described type VI system, the toxin blocks replication elongation by directly binding to the $\beta$ sliding clamp DnaN, whereas the antitoxin promotes toxin degradation by ClpXP [3]. Type I antitoxins interact with their toxin mRNAs that mostly code for small hydrophobic peptides recruited to the cell membrane, but also for RNA or DNA cleaving enzymes (rev. in [4]). The first TA systems have been found on plasmids, where they act as post-segregational killing (PSK) systems (rev. in [5]). Subsequently, a multitude of TA systems were discovered on bacterial chromosomes (e.g., [6]).

Type I TA systems have been found in many Gram-positive and Gram-negative species, and some of them were investigated in great detail (e.g., hok/Sok, rev. in [5]; or fst/RNAI, rev. in [7,8]). TA loci 
are arranged as overlapping, convergently transcribed gene pairs or as divergently transcribed pairs located apart (rev. in [4]). In the first ones, the antitoxin is a cis-encoded antisense RNA (e.g., hok/Sok, rev. in [9]; txpA/RatA [10,11]; aapA1/IsoA1 [12]), in the latter ones, it is a trans-encoded sRNA (e.g., tisB/IstR1, rev. [13]; zor/Orz, ibs/Sib and shoB/OhsC, rev. in [14]). In some cases, deletion of the antitoxin gene results in cell lysis [15], in others, only toxin overexpression impairs growth (zor/Orz, tisB/IstR1). Whereas TA pairs on plasmids act as PSK required for plasmid maintenance (e.g., hok/Sok on E. coli plasmid R1 or $f s t / R N A I I$ on $E$. faecalis plasmid pAD1, rev. in [7,8]), the biological function of many chromosomal TA loci is still poorly understood. E. coli symE/SymR was proposed to be involved in recycling of damaged RNA generated upon SOS stress (rev. in [16]), dinQ/AgrB in chromosome stability [17] and $\mathrm{ralR} / \mathrm{RalA}$ in resistance against cell-wall inhibiting antibiotics [18]. By contrast, for E. coli tisB/IstRI and hokB/SokB as well as Streptococcus mutans fstSm/SrSm, a role in persister formation has been demonstrated (rev. in [4]), [19]. B. subtilis txpA/RatA probably helps-similar to plasmid-encoded PSK systems - to maintain the skin element, which is excised from the chromosome during sporulation, thereby allowing reconstitution of a functional sigK gene [10]. In other cases, it was speculated that toxin expression might be advantageous upon stress, as shown for some type II TA systems (rev. in [9]).

In B. subtilis, 14 type I TA systems were proposed [20], and five of them are located on prophage regions. Three of them—txpA/RatA [10,11], bsrG/SR4 [15] and bsrE/SR5 [21,22]—have been investigated in more detail. $b s r G / S R 4$ located on SP $\beta$ prophage is the first discovered temperature-sensitive type I TA system, as $b s r G$ RNA is rapidly degraded at $48{ }^{\circ} \mathrm{C}$. SR4 is a bifunctional antitoxin that promotes bsrG RNA degradation by recruiting RNase III, and additionally induces a structural change around the $b s r G$ RBS that further obstructs translation [23]. The toxin BsrG (38 aa) is recruited to the cell membrane, but does not dissipate the membrane potential. Instead, it generates membrane invaginations causing delocalization of the cell-wall synthesis machinery, which finally results in autolysis [24]. bsrE/SR5 is a multistress-responsive TA system encoded on the prophage-like region P6 [21]. The secondary structures of bsrE RNA and bsrG RNA are very similar, and binding between toxin mRNA and the cognate antitoxin occurs in both systems via three subsequent steps [22]. However, SR5 is-in contrast to SR4-a monofunctional antitoxin that only promotes degradation of its bsrE toxin mRNA by recruiting RNase III. Both $b s r E$ mRNA and SR5 are rapidly degraded by RNase Y upon ethanol stress. Whereas $b s r E$ RNA is influenced by temperature shock and alkaline stress, SR5 is rapidly degraded under $\mathrm{O}_{2}$ limitation and affected by $\mathrm{pH}$ stress and iron limitation [21].

Here, we confirm experimentally previous data $[6,20]$ that yonT/SR6 is the second type I TA system located on the SP $\beta$ prophage of the B. subtilis chromosome. We identified the transcription start points of yonT mRNA and SR6 and analyzed the expression profiles of both RNAs in different media and under stress conditions. Furthermore, we determined the strength of the yonT and sr6 promoters. In addition, we calculated the half-lives of toxin mRNA and RNA antitoxin. YonT proved to be so toxic that only a mutated yonT gene containing a stop instead of a start codon could be cloned in E. coli and established in B. subtilis. Determination of the intracellular concentrations of both complementary RNAs showed that SR6 is present at least at 10- to 25-fold higher concentrations than yonT or yoyJ mRNA under most growth conditions. We demonstrate by Northern blotting that SR6 acts by promoting yonT mRNA degradation. Furthermore, we provide indirect evidence that yoyJ whose RBS is complementary to the $5^{\prime}$ end of SR6 is a second, albeit weaker, toxin that might be also inhibited by SR6. A BLAST search for homologues of yonT, yoyJ and sr6 revealed that yonT and sr6 are encoded in five Bacillus species, whereas the yoyJ gene or its promoter was mutated, so that no functional protein can be expressed.

\section{Results}

\section{1. yonT Is Located in an Operon, and Transcripts of Different Length Originate from $p_{\text {yonT }}$}

First, we performed Northern blots with total RNA isolated from B. subtilis wild-type strain DB104 grown in complex TY medium and probes against yonT RNA, yonU RNA and antisense-yonT RNA 
(renamed as SR6). Surprisingly, we detected yonT RNA species of different length from the predicted 217 over 527 to $1 \mathrm{~kb}$ and longer (Figure 1A) suggesting that yonT is located in an operon with adjacent genes. SR6 of the expected length of $\approx 100 \mathrm{nt}$ was observed, but in addition at $\mathrm{OD}_{600}=3.0$ a longer SR6 transcript of $\approx 215 \mathrm{nt}$ was detected. Second, to investigate if yonT is transcribed under an own promoter $\mathrm{p}_{y o n} \mathrm{~T}$ or from the upstream yonS promoter $\mathrm{p}_{y o n s}$ and is located in an operon together with the downstream genes yoyJ, yonU and yon $V$, we performed RT PCR with the same total RNA treated with DNase and primers for the detection of yonT, yonU, yonV and yoyJ transcripts. In parallel, this RNA was employed for RT-PCR with primers against SR6. Chromosomal DNA from strain DB104 served as positive control for the expected PCR fragments. Primers against gapA RNA were used as control for the purity and applicability of the isolated DNase-treated RNA (Figure S1). As shown in Figure 1A and supported by the RT-PCR results in Figure 1B, one long mRNA comprising yonT, yoyJ, yon $U$ and yon $V$ was detectable that is transcribed from promoter $\mathrm{p}_{y o n T}$. Furthermore, a short $217 \mathrm{nt}$ monocistronic yonT mRNA and a bicistronic yoyJ/yonU transcript - both apparently processing products of the long RNA-are visible. In addition, a tricistronic yonT/yoyJ/yonU transcript was found. Furthermore, a monocistronic yon $U$ transcript was observed that might be transcribed from its own promoter downstream of yoyJ and terminated downstream of yonU. SR6 of the expected size could also be confirmed. An additional Northern blot with riboprobes against the upstream and downstream region of SR6 revealed that the $\approx 215 \mathrm{nt}$ SR6 species observed at the transition to stationary growth phase at $\mathrm{OD}_{600}=3-4$ indeed originated from $\mathrm{p}_{S R 6}$ and extended at least towards $\mathrm{p}_{\text {yonT }}$. No signal was obtained with a probe against a sequence upstream of SR6 (not shown). Figure 1C summarizes all transcripts detected in Northern blots including the long transcript confirmed by RT-PCR in the region between $\mathrm{p}_{y o n T}$ and $\mathrm{p}_{y o n V}$.
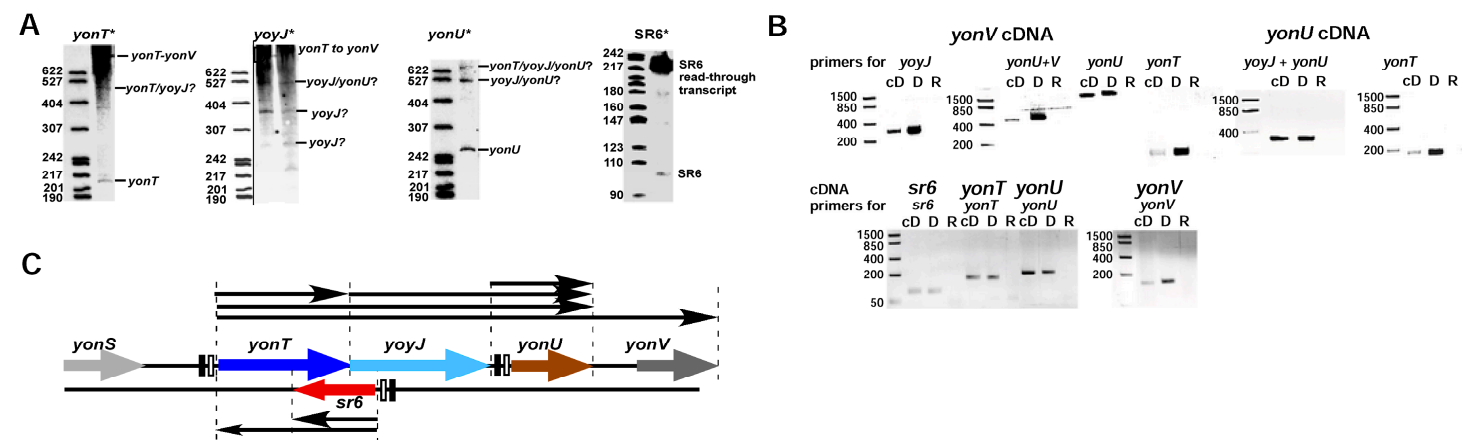

Figure 1. Determination of transcripts within the yonSTUV operon by RT-PCR. B. subtilis DB104 was grown in TY medium until $\mathrm{OD}_{600}=3.0$ (transition phase), total RNA isolated, treated with DNase and used as template for RT-PCR. (A) Northern blots. B. subtilis strain DB104 was grown at $37^{\circ} \mathrm{C}$ in TY, aliquots taken at different times, immediately frozen in liquid nitrogen and later on used for the preparation of total RNA. RNA was separated on $6 \%$ denaturing PAA gels, blotted onto nylon membrane and hybridized with riboprobes against yonT mRNA, yoyJ mRNA, yonU mRNA and SR6. Autoradiograms of the corresponding gels are shown; (B) Original data of RT-PCR. B. subtilis DB104 was grown in TY medium until $\mathrm{OD}_{600}=3.0$ (transition phase), total RNA isolated, treated with DNase and used as template for RT-PCR. PCR products were analysed in ethidium-bromide stained 3\% agarose gels. cD, cDNA; D, genomic DNA; R, total RNA; $(C)$ Graphic summary of the transcripts in the yonSTUV region based on the RT-PCR data and Northern blots.

\subsection{Mapping of $5^{\prime}$ and $3^{\prime}$ Ends of yonT RNA, SR6 and yonU RNA}

An sRNA antisense to yonT was first detected by Fozo et al. [6]. To conform to the other known B. subtilis TA systems [20], we renamed antisense-yonT as SR6 (see above) and determined the transcriptional start sites of yonT mRNA, SR6 and yonU mRNA. The latter was included to confirm that yon $U$ is transcribed from an own promoter ( -10 box: TATAAT 120 bp upstream of the TTG start 
codon) as depicted in Figure 1C. Figure 2A presents the chromosomal location of the yon region and Figure $2 \mathrm{~B}$ the results of the $5^{\prime}$ end mapping. No typical rho-independent terminators were found downstream of yonT, yoyJ and yonU, indicating that the monocistronic yonT, yon $U$ and yoyJ transcripts are most likely processing products. As S1 mapping also did not allow the exact determination of the $3^{\prime}$ ends, the RNA sizes calculated by Northern blotting (see Figure 1A and below) were used to narrow down the $3^{\prime}$ ends of monocistronic yonT RNA, monocistronic yonU RNA and SR6. All three RNAs are transcribed from $\sigma^{\mathrm{A}}$ promoters, and $\mathrm{p}_{\text {sr } 6}$ and $\mathrm{p}_{\text {yonT }}$ have extended -10 boxes. SR6 and yonT overlap by $\approx 65 \mathrm{nt}$ at their $3^{\prime}$ ends, whereas sr 6 and yoyJ overlap by $\approx 30$ to $40 \mathrm{nt}$ at their $5^{\prime}$ ends. Figure $2 \mathrm{C}$ displays the complete nucleotide sequence of the yonT/sr6/yoyJ locus.

A

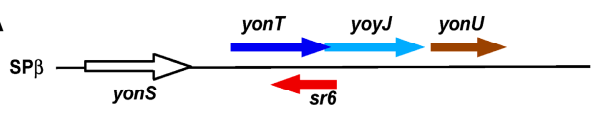

B

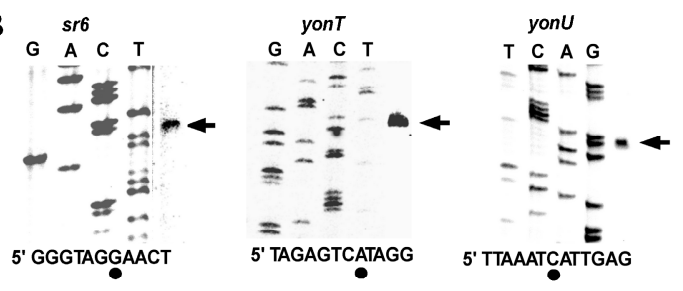

C

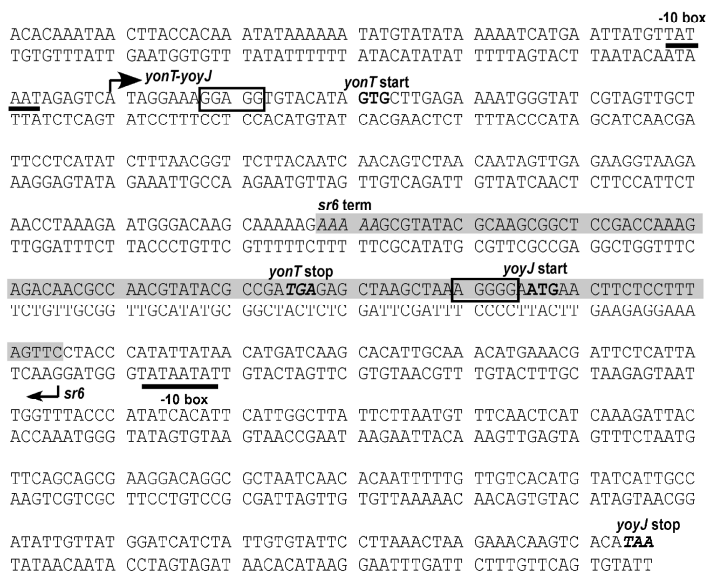

Figure 2. Location of the yonT/sr6/yoyJ/yonU locus and determination of transcription start sites. (A) Schematic representation of the location of the yonT/sr6/yoyJ/yonU locus on the B. subtilis chromosome. The directions of transcription are indicated by arrows; (B) Mapping of the $5^{\prime}$ ends of yonT mRNA, yonU mRNA and SR6. Sanger sequencing reactions of heterologous genes were used as references to calculate the location of the transcription start signals. Outer right lanes show primer extension reactions on total RNA of B. subtilis DB104 with 5'-labelled primer SB2648 (sr6), SB2646 (yonT), and SB2647 (yonU) loaded in parallel to the sequencing reactions (transcription start sites are indicated by arrows). Below: sr6, yonT and yonU sequences around the TSS are shown. Dots symbolize the mapped TSS; (C) Sequence of the yonT/yoyJ/sr6 locus. -10 boxes of the yonT and the sr6 promoters are underlined. Start and direction of transcription are indicated by arrows and transcription termination is indicated by 'term'. The yonT/SR6/yoyJ complementary region is highlighted in light grey. Start and stop codons of the yonT and yoyJ ORFs are in bold and the putative SD sequences are boxed.

\subsection{Expression Profiles of yonT $m R N A$, yoyJ mRNA, yonU mRNA and SR6 in Complex TY and Minimal CSE Medium}

The expression patterns of yonT RNA, yoyJ RNA and SR6 were analyzed by Northern blotting after growth of B. subtilis strain DB104 at $37^{\circ} \mathrm{C}$ in either complex TY or minimal CSE medium with glucose (CSEG) or without glucose (CSE). The Northern blots are displayed in Figure 3A and graphs for the calculation of RNA amounts in Figure 3B. To determine the ratio between yonT toxin mRNA and antitoxin SR6, defined amounts of in vitro synthesized yonT RNA and SR6 were loaded onto the same gel and hybridized with the same riboprobes (entire blots are shown in Figure S2). The calculations of the SR6/yonT RNA ratios over growth in all three media are summarized in Figure 3A below the autoradiograms of the Northern blots. 
A

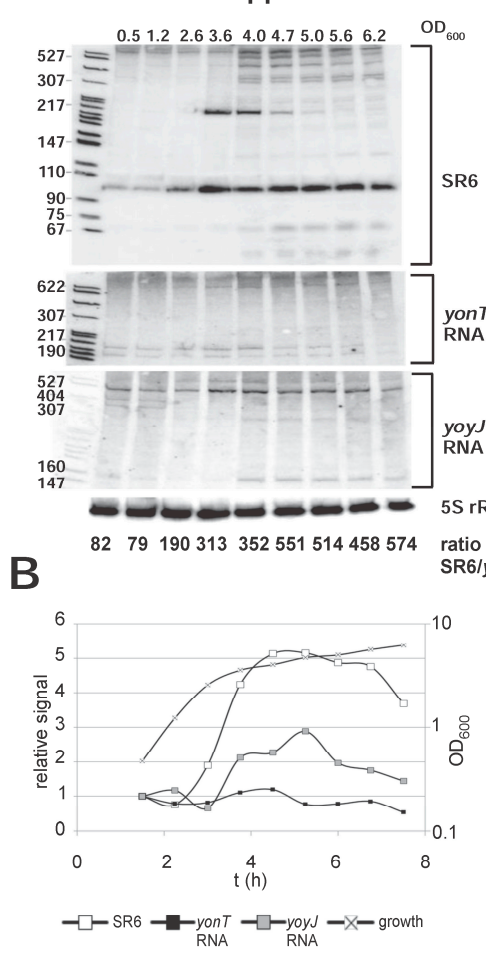

CSEG

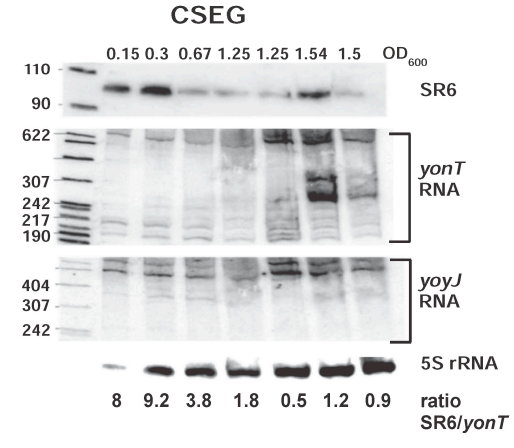

CSE
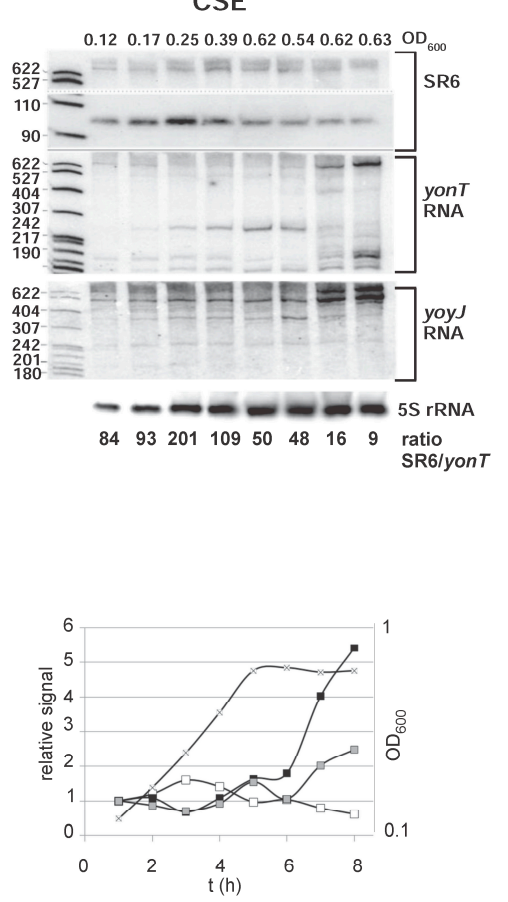

Figure 3. Expression profiles and concentrations of yonT mRNA, yoyJ mRNA and SR6 in complex TY and minimal CSE medium. (A) Northern blots. B. subtilis strain DB104 was grown at $37{ }^{\circ} \mathrm{C}$ in TY or CSE medium, and RNA isolation, Northern blotting and reprobing performed as in Figure 1. For the correction of loading errors, filters were reprobed with $\left[\gamma^{-32} \mathrm{P}\right]$ ATP-labeled oligonucleotide C767 specific for 5S rRNA. Autoradiograms of the corresponding gels are shown. The SR6/yonT RNA ratios shown below the Northern blots are derived from the calculations represented by graphs in (B). Graphic representation of the amounts of yonT RNA, yoyJ RNA and SR6 based on the quantification of the gels shown in (A) and Figure S2. The corresponding growth curves are shown using the $\mathrm{Y}$ axis at the right side of each graph.

In TY medium, the amount of yonT mRNA was nearly unchanged over time. By contrast, the amount of yoyJ mRNA was two- to threefold higher in stationary phase. The amount of the antitoxin SR6 increased 5-fold from early log until transition to stationary growth phase and then slightly decreased in stationary phase (Figure 3A). Here, the SR6/yonT RNA ratio increased from 82 in $\log$ phase to 313 in transition phase and was 574 in late stationary phase indicating that under these conditions, toxin expression is strongly inhibited. By contrast, in CSEG medium, the amount of yonT RNA increased about four- to five-fold until stationary phase, whereas the amount of SR6 decreased at the same time about four- to five-fold, resulting in lowest SR6/yonT RNA ratios between 0.46 and 1.22 in stationary phase. This indicates that from transition phase until late stationary phase, yonT might be expressed in some cells. The amount of yoyJ RNA was nearly constant over growth. In CSE medium, the amount of SR6 was more or less constant over growth, whereas the amount of yonT mRNA increased in stationary phase nearly six-fold. Therefore, the SR6/yonT mRNA ratio decreased from logarithmic to stationary phase from $80-100$ to $\approx 9$, but was always in a range that would not allow toxin expression. The amounts of yoyJ RNA increased about two-fold towards stationary phase.

In summary, we can conclude that the amount of SR6 increased only in TY medium significantly towards stationary phase, whereas it was nearly constant in CSE. As, however, the amount of yonT RNA displayed a 4 or 5.5-fold increase in CSEG and CSE, respectively, the SR6/yonT ratio decreased in these media. But only in CSEG this ratio fell to about 1 , so that only in this medium toxin expression might be expected. 


\subsection{The sr6 Promoter Is Weaker than the yonT Promoter}

To analyze activities of the promoters $p_{y o n T}$ and $p_{s r 6}, \beta$-galactosidase measurements with transcriptional lacZ fusions were performed in TY, CSE and CSEG in early and late logarithmic and in stationary growth phase (Figure 4). To this end, transcriptional lacZ fusions comprising $500 \mathrm{bp}$ upstream of the -35 boxes of $\mathrm{p}_{y o n T}$ (plasmid pMGC1) and $\mathrm{p}_{s r 6}$ (pMGC14) integrated into the amyE locus of strain DB104. Two additional plasmids, pMGC6 and pMGC8 carrying only 100 or 240 bp upstream of the -35 boxes, were also constructed.
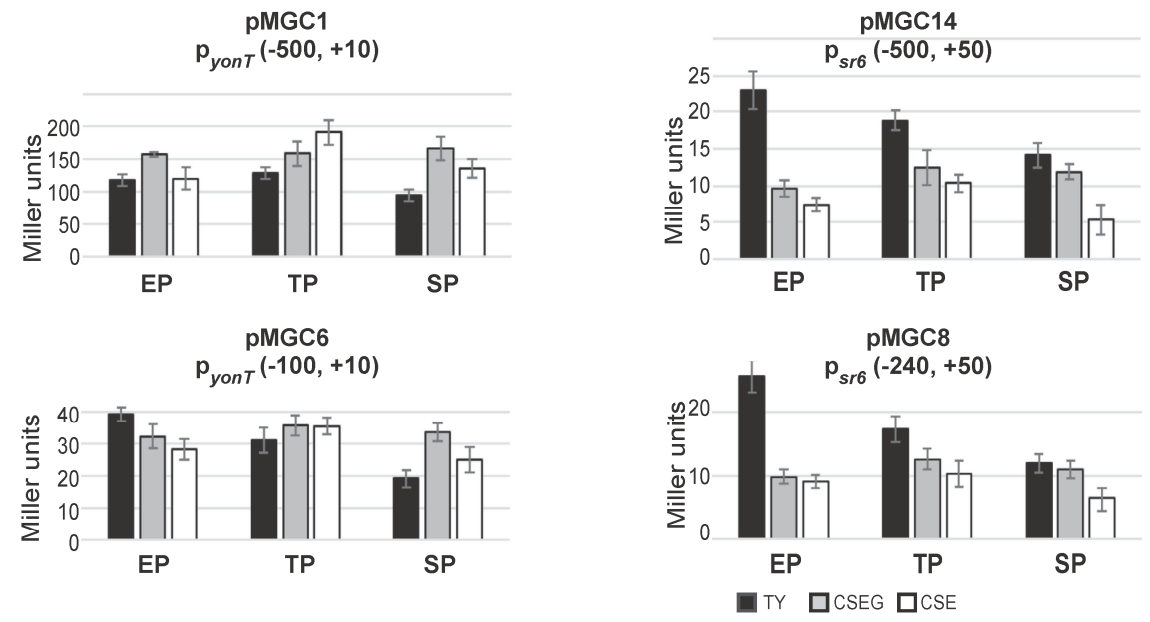

Figure 4. Activities of the yonT promoter and the sr6 promoter in TY (black), CSEG (grey) and CSE (white) medium over growth. B. subtilis strains generated by integration of the indicated vector fragments into the amyE locus of DB104 were grown in TY, CSEG or CSE medium. In early exponential phase (EP), late exponential phase/transition phase (TP) or stationary phase (SP) samples were withdrawn and used for $\beta$-galactosidase measurements. Averages of three independent measurements with standard deviations are shown. Vector pMG16 without a promoter insert yielded in all tested media values between 1 and 3 Miller units.

As shown in Figure 4, between media and growth phases, no significant differences in the activities of $\mathrm{p}_{y o n T}$ could be found. The $\mathrm{p}_{\text {yon }} \mathrm{T}$-lac $Z$ fusion with the $500 \mathrm{bp}$ promoter upstream region revealed in all three growth phases activities between 100 and 200 MU. In TY and CSEG medium, only a slight alteration during growth was observed, whereas in CSE medium a two-fold increase only in late exponential phase was determined. By contrast, the $\mathrm{p}_{\text {yon }} \mathrm{I}_{\text {-lac }} \mathrm{Z}$ fusion with the short $(100 \mathrm{bp})$ promoter upstream region (pMGC6) revealed with 20-40 MU four- to five-fold lower activities. In TY, activities decreased from exponential to stationary phase about 2-fold, whereas in CSEG and CSE no significant alterations were observed. The activities of $\mathrm{p}_{s r 6}$ were with 15 to $25 \mathrm{MU}$ very low. This was unexpected, as type I antitoxins are usually transcribed from rather strong promoters (e.g., a $\mathrm{p}_{s r 4}$-lac $Z$ fusion yielded between 750 and $3000 \mathrm{MU}$ [15]). However, measurements with an empty vector yielding $0.5 \mathrm{MU}$ (early log phase) to $3 \mathrm{MU}$ (stationary phase) confirmed that $\mathrm{p}_{s r 6}$ was not inactive. The constructs pMGC14 $(-500,+50)$ and pMGC8 $(-240,+50)$ displayed in TY a two-fold activity decrease from early log to stationary phase, whereas in CSE and CSEG only marginal changes were observed. Similar low activities (15-27 MU) were measured for $\mathrm{p}_{y o n}$ in all growth phases and media (not shown).

In summary, the measured activities of $\mathrm{p}_{\text {sr }}$ were in all growth media and stages between 20- and two-fold lower than those of $\mathrm{p}_{\text {yon } T}$. The activities of $\mathrm{p}_{y o n}$ were four- to five-fold higher in constructs with a $500 \mathrm{bp}$ promoter upstream region compared to those with only a $100 \mathrm{bp}$ promoter upstream region suggesting a possible regulation by a transcriptional activator. Whereas $\mathrm{p}_{\text {yon }}$ activities were essentially independent of the growth medium, $\mathrm{p}_{\text {sr } 6}$ activities were-at least in early log phase-highest in TY medium. 
2.5. Overexpression of yoyJ Impairs the Establishment of Transformants in B. subtilis Indicating That It Is Also a Toxin

As SR6 is not only complementary to the $3^{\prime}$ region of yonT mRNA, but also to the $5^{\prime}$ region including the RBS of yoyJ (see Figure 2A,C), it was previously hypothesized [20] that YoyJ might be also a toxin, and its expression inhibited by SR6. To investigate this issue, we constructed pUCBYJ, a multicopy E. coli/B. subtilis shuttle vector ( $\approx 50$ copies/cell) that allows for overexpression of yoyJ in both E. coli and B. subtilis. Already upon transformation of E. coli we observed rather small transformant colonies that grew much slower than those of pUCBas used for overexpression of the complete sr6 gene. Therefore, we decided to compare the transformation efficiency of pUCBYJ in B. subtilis with that of pUCBas (encoding sr6) and pUCBYU encoding yonU that is not proposed to be a toxin. As control served the empty vector pUCB2. In parallel we used B. subtilis strain 1A100 lacking the prophage $\mathrm{SP} \beta$ that does not encode yonT/yoyJ/sr6 and DB104 containing SP $\beta$, and, thus, expressing the entire yonSTUV operon including sr6. As shown in Figure 5, the transformation efficiencies of pUCBas and pUCBYU were comparable in both strains, while the empty vector pUCB2 yielded about 5 times more colonies. By contrast, pUCBYJ could not be established in strain 1A100 that does not express the antitoxin SR6, whereas it yielded a few transformants in DB104. When we grew three DB104(pUCBYJ) transformants alongside three DB104(pUCBas) transformants, they did not display altered growth (not shown). Initially we suspected that they might have undergone mutations in the yoyJ gene, but sequencing of 10 clones demonstrated that this was not the case.

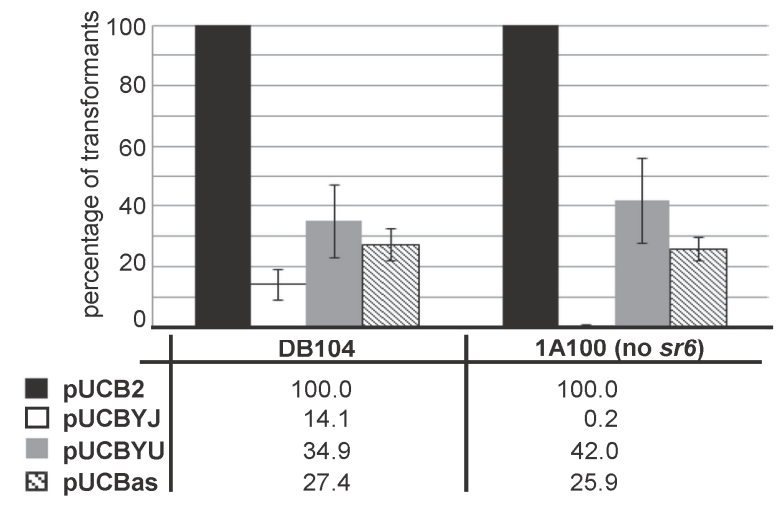

Figure 5. Establishment of transformants overexpressing yoyJ in B. subtilis in the presence and absence of sr6. B. subtilis strains DB104 (wild-type) and 1A100 ( $\Delta \mathrm{SP} \beta$, i.e., $\Delta[$ yonT/yon $Y /$ sr6]) were transformed with $5 \mu \mathrm{g}$ purified plasmids pUCB2 (empty vector control), pUCBYJ (overexpression of yoyJ), pUCBYU (overexpression of yon $U$ ) and pUCBas (overexpression of $s r 6$ ), transformants selected for kanamycin resistance and counted. The number of pUCB2 transformants was set to $100 \%$. Shown data are the average of four independent experiments.

In summary, we can conclude that YoyJ is, in addition to YonT, most probably also a toxin, although its toxicity is much lower than that of YonT.

\subsection{SR6 Is Significantly More Stable than yonT $m R N A$}

Half-lives of yonT RNA and SR6 were determined in B. subtilis $1 \mathrm{~A} 100$ in TY at $\mathrm{OD}_{600}=3.0$, i.e., at transition to stationary phase when both long and short SR6 species were visible. A yonT overexpression plasmid was used, as the signals from the chromosomal yon $T$ gene in Northern blots were extremely weak (see Figure 3) impeding an exact calculation of a progressive decrease over time. The yonT RNA proved to be unstable with a half-life of $8 \mathrm{~min}$ (Figure 6A). The half-life of the $100 \mathrm{nt}$ SR6 species was $\approx 60 \mathrm{~min}$, whereas the $215 \mathrm{nt}$ SR6 species was extremely stable with a half-life of $>120 \mathrm{~min}$. 
A

$1 \mathrm{~A} 100$

PAPYT3 + pUCB2

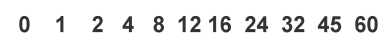
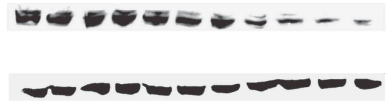

1.0

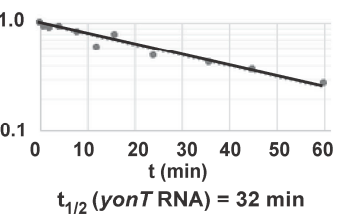

B

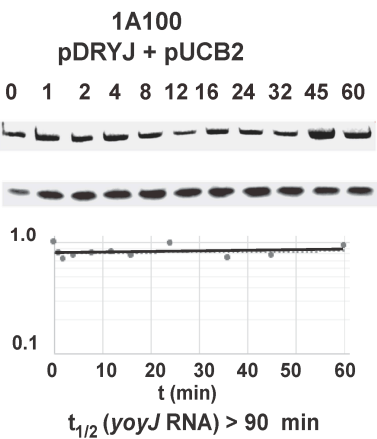

PAPYT3 + pUCBas

$\begin{array}{lllllllllllll}\mathrm{t}(\min ) & 0 & 1 & 2 & 4 & 8 & 12 & 16 & 24 & 32 & 45 & 60 & \mathrm{t}(\mathrm{min})\end{array}$

yOnT RNA $=-\mathbf{m}=-\mathbf{m}$
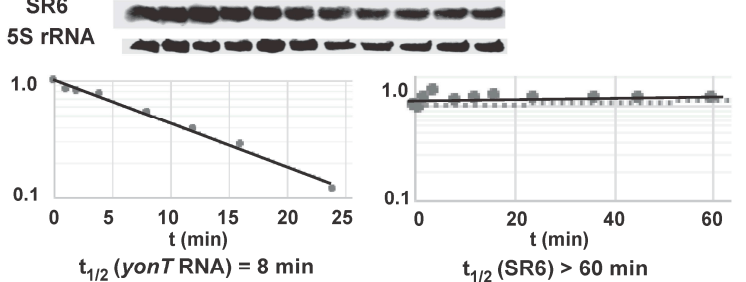

$\mathrm{t}_{1 / 2}($ yonT RNA $)=8 \mathrm{~min}$

$1 \mathrm{~A} 100$ pDRYJ + pUCBas

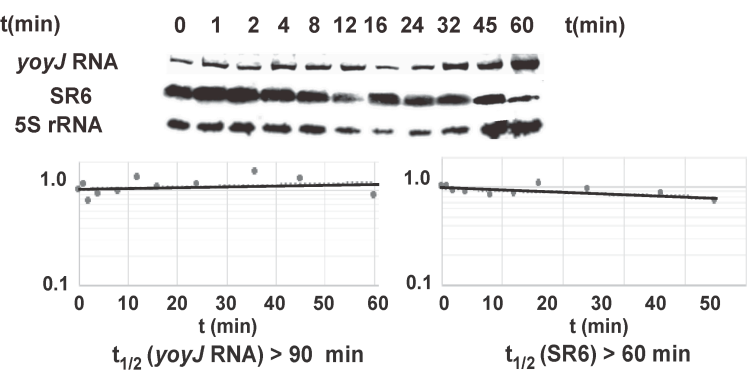

Figure 6. Determination of the half-lives of yonT mRNA and SR6 (100 nt) in complex TY medium. Half-lives were determined as described (Materials and Methods). Samples were taken at the indicated times after addition of $200 \mu \mathrm{g} / \mathrm{mL}$ rifampicin at $\mathrm{OD}_{600}=3.5$. [ $\left.\alpha{ }^{32} \mathrm{P}\right]-\mathrm{UTP}-$ labeled riboprobes for yonT RNA and SR6 were used. Reprobing was performed as in Figure 3. Autoradiograms of the Northern blots are shown. Indicated half-lives are averaged from three independent determinations. (A) Determination of half-lives of yonT RNA expressed from overexpression plasmid pAPYT3; (B) Determination of half-lives of yoyJ RNA expressed from overexpression plasmid pDRYJ1. Strain 1A100 (no sr6 gene) containing either pAPYT3 or pDRYJ1 combined with either pUCB2 (vector pUCB2) or pUCBas (pUCB2 with sr6 gene under own promoter) were grown in TY with IPTG to induce yonT and yoyJ transcription, respectively.

\subsection{SR6 Promotes Degradation of yonT RNA, but Does Not Affect the Stability of yoyJ RNA}

In many type I TA systems, the antitoxin promotes degradation of the toxin mRNA. To determine whether SR6 affects stability of yonT mRNA, SR6 was expressed in strain 1A100 from multicopy plasmid pUCBas and the empty vector pUCB2 served as negative control. The toxin gene yonT was expressed in the same strain from the chromosome using an integration vector (pAPYT3). Since we could not clone wild-type yonT in any tightly regulated inducible, high or low copy vector in $E$. coli (which is the prerequisite for analyzing yonT expression in B. subtilis 1A100) - even in the presence of a plasmid expressing sr6-we had to resort to cloning of a yonT gene with a start- to stop codon mutation (pAPYT3). In the absence of SR6, the half-life of yonT mRNA was $\approx 32 \mathrm{~min}$, and it decreased to $\approx 8 \mathrm{~min}$ in the presence of SR6 (Figure $6 \mathrm{~A}$ ). With a half-life of $>60 \mathrm{~min}$, the stability of SR6 was not affected even by overexpression of yonT mRNA. This was not unexpected as we determined a high (300-350-fold in transition phase) excess of SR6 over yonT RNA during growth in TY medium (Figure 3A). As SR6 might also affect the half-life of yoyJ mRNA encoding the second toxin (see above), wild-type yoyJ was expressed from an integration vector (pDRYJ) in strain 1A100 either in the presence (pUCBas) or absence (pUCB2) of SR6. In both cases, yoyJ RNA was very stable with a half-life of $>90 \mathrm{~min}$, whereas the half-life of SR6 was not affected by yoyJ mRNA (Figure 6B).

Therefore, we can conclude that SR6 promotes degradation of yonT mRNA whereas it does not affect the stability of yoy J mNA. 


\subsection{The Amounts of yonT RNA and SR6 Are Affected by Different Stress Conditions}

To identify factors that might impact yonT or sr6 expression, DB104 was cultivated until onset of stationary phase in TY medium, different stress conditions were applied, time samples taken over $60 \mathrm{~min}$, total RNA prepared and subjected to Northern blotting (Figure 7). To find out if the stress effects depend on the alternative sigma factor $\sigma^{B}$, a $\operatorname{sig} B$ knockout strain was used in parallel. The following stress conditions, which did not impair cell viability, were tested as described in Materials and Methods: Cell wall stress (vancomycin), manganese stress, heat-shock, ethanol stress, iron limitation, oxidative and salt stress as well as anaerobic stress with nitrate respiration. The latter stress had no pronounced effects on either RNA (not shown). The effects of the other stress conditions are discussed below and summarized in Figure 7.

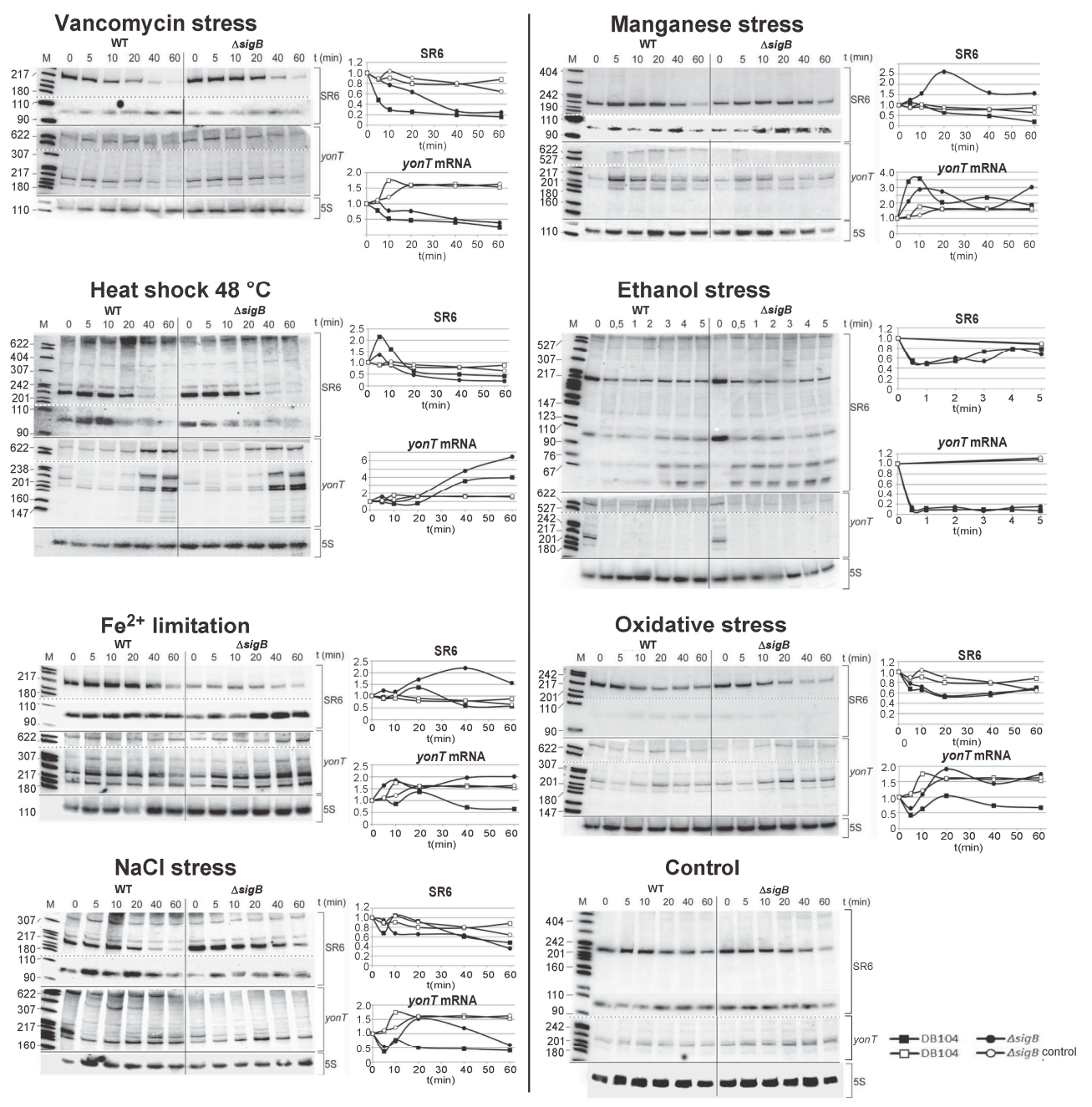

Figure 7. Stress conditions that influence the amounts of yonT RNA and SR6. B. subtilis strain DB104 was cultivated in TY at $37{ }^{\circ} \mathrm{C}$ until onset of stationary phase, stress factors applied as described in Materials and Methods, time samples withdrawn after indicated times, RNA prepared and subjected to Northern blotting as in Figure 1. Wild-type and $\Delta \operatorname{sig} B$ strains were compared. Analysis of cell wall (vancomycin) stress, heat shock, $\mathrm{Fe}^{2+}$ limitation, salt, manganese, ethanol stress, and oxygen stress. Furthermore, a control blot without applied stress factors at $37^{\circ} \mathrm{C}$ is included. Next to each Northern blot, the graphic representation of the stress effects on yonT RNA and SR6 are displayed. The Y axis refers to the relative amount of the corresponding RNA. The results of two or three independent experiments are shown. 
The strongest effect was observed upon addition of ethanol. Within $0.5 \mathrm{~min}$, yonT mRNA disappeared completely. By contrast, the amount of SR6 was only two-fold reduced after $1 \mathrm{~min}$ and increased to $80 \%$ of its initial amount after $5 \mathrm{~min}$. In both cases, the effects were $\operatorname{sig} B$ independent.

Addition of vancomycin (cell-wall stress) resulted in a five-fold decrease in the amount of SR6 after $20 \mathrm{~min}$ whereas the amount of yonT RNA decreased four-fold after $60 \mathrm{~min}$. Both effects were sigB independent.

After heat shock (from $37^{\circ} \mathrm{C}$ to $48^{\circ} \mathrm{C}$ ), a four-fold increase in the amount of yonT mRNA was observed whereas the amount of SR6 decreased four-fold after $60 \mathrm{~min}$, both sigB independently. This is in stark contrast to the heat-shock effects on $b s r G$ and $b s r E$ toxin mRNAs, whose amounts both decreased 10-fold while the amounts of the cognate antitoxins SR4 and SR5 were unaffected [15,21].

Upon manganese stress, the amount of SR6 decreased four-fold after $60 \mathrm{~min}$, whereas the amount of yonT RNA increased 3.5-fold after $10 \mathrm{~min}$ followed by a decrease after $20 \mathrm{~min}$ to the duplicate of the initial amount, both independent of $\operatorname{sig} B$.

Lower effects were found upon iron limitation (two-fold decreased amounts of both SR6 and yonT RNA), oxidative stress (two-fold decrease of SR6, no significant effect on yonT RNA), and salt stress (two-fold decrease of yonT RNA, at the most two-fold effect on SR6). Interestingly, oxidative stress and iron limitation were the only stress conditions that depended on $\operatorname{sig} B$.

Taken together, we can conclude that yonT/SR6 is a multistress-responsive type I TA system.

\subsection{Homologues of the yonT, yoyJ and sr6 Are Present in Some Other Bacillus Species}

An inspection of all currently published genomes for homologues to yonT, yoyJ and sr6 revealed DNA sequences of high similarity in Bacillus subtilis, Bacillus amyloliquefaciens XH7, Bacillus atrophaeus NRS 1221A, Bacillus methylotrophicus JJ-D34 and Bacillus velezensis CC09 (Figure 8). The yonT DNA sequence and the YonT aa sequence were highly conserved in all five strains, the latter displaying only a few aa exchanges. In addition, a protein BLAST revealed a highly similar YonT protein comprising 66 aa in B. nakamurai and a shortened, 37 aa homologue lacking the YonT C terminus in B. vallismortis. The $s r 6$ gene was also highly conserved in the five species mentioned first. In all cases, an extended -10 box of $\mathrm{p}_{s r 6}$ was detectable and only the first transcribed nt showed a few variations. By contrast, only B. subtilis does encode the complete yoyJ ORF. In B. atrophaeus, B. methylotrophicus and B. velezensis, the ATG start codon and the following 11 codons of yoyJ are missing and the shortened ORF starting with the second ATG is not preceded by a RBS, while the B. amyloliquefaciens yoyJ ORF carries a premature stop codon after codon 12 making it in all these cases unlikely that a functional YoyJ protein is synthesized. 
$3^{\prime}$ end, in bsrE RNA 7-9 nt from the $3^{\prime}$ end. In contrast to SR5, SR4 is a bifunctional antitoxin as it does not only promote $b s r G$ mRNA degradation but also impedes its translation by inducing a structural change that obscures the bsrG RBS [23]. As with translational yonT-lacZ fusions, no differences in translational activities could be observed in the absence or presence of SR6 (Table S1), a translation inhibition of yonT by SR6 is improbable. However, the measured $\beta$-galactosidase activities were only slightly above the negative control. Therefore, other experiments are required to corroborate these results.

Whereas SR6 acts like SR4 and SR5 by binding to the $3^{\prime}$ end of the toxin yonT RNA to promote its degradation, it overlaps the $5^{\prime}$ region of the second toxin gene, yoyJ, by approximately $30-40 \mathrm{bp}$. As we demonstrate in Figure 6, SR6 does not induce degradation of yoyJ mRNA. Unfortunately, employing a translational yoyJ-lacZ fusion under control of the strong promoter pIII [25] we could only measure activities barely above the levels of the empty vector control (Table S1), both in logarithmic or early stationary phase in the presence (strain DB104) and absence (strain 1A100) of SR6. Therefore, we resorted to in vitro yoyJ translation to analyze a possible effect of SR6. However, no in vitro translation product of yoyJ could be detected. The reason is the short distance (4 nt) between SD sequence and yoyJ start codon that makes yoyJ translation extremely inefficient (see Figure 2C).

However, transformation experiments provided an indirect evidence for the toxicity of YoyJ: B. subtilis strain A100 devoid of the yonT/yoyJ/SR6 system could not be transformed by plasmid pUCBYJ for constitutive yoyJ expression, whereas DB104 encoding SR6 as single copy on its chromosome, could, albeit with a somewhat lower efficiency than the same vector encoding yonU or sr6 itself (Figure 5). Although this data is only an indirect evidence, it shows that yoyJ does encode a toxin, albeit one with considerable lower toxicity than YonT. The low toxicity of YoyJ might be due to its very weak translation. For YonT it was not possible to construct an inducible overexpression E. coli-B. subtilis shuttle vector even with a medium copy number and a tightly controlled promoter. This was in contrast to a former publication that reported the construction of an E. coli plasmid for inducible overexpression of yonT under the $\mathrm{pBAD}$ promoter [6]. We assume that a mutation occurred either in the constructed plasmid or the E. coli strain that decreased toxicity of YonT and allowed to establish this plasmid in E. coli.

The growth and establishment effects suggest a slightly toxic function of the yoyJ gene. The antitoxin SR6 carries a complementary region to the $5^{\prime}$ end of yoyJ which is uncommon in type I TA systems of Gram-positive bacteria, but a characteristic of Gram-negative bacterial type I TA systems such as hok/Sok or ibs/Sib of E. coli (rev. in [4]). At the moment, the molecular mechanism by which SR6 neutralizes the toxicity of YoyJ is unknown. A BLAST search showed that yonT is well conserved in five Bacillus species, among them B. amyloliquefaciens and B. atrophaeus (Figure 8). By contrast, the yoyJ gene carries different mutations in other Bacillus species, e.g., an early stop codon in B. amyloliquefaciens and a mutated start codon in the other three species which indicates that YoyJ is not synthesized in other species.

\subsection{Antitoxin/toxin RNA Ratios and Half-Lives}

In cis-encoded sense/antisense RNA systems-to which type I TA systems belong-the amount of the antisense RNA has to be 5- to 10-fold higher than that of the sense RNA to ensure proper control (rev. in [26]). This has been also confirmed by quantitative measurements for type I TA systems $b s r G / S R 4$ [27] and bsrE/SR5 [21]. In complex TY medium, the SR4/bsrG RNA ratio fell below 1.0 already at late log phase and decreased further drastically in stationary phase to 0.2 [27]. Similar results were obtained for $b s r E / S R 5$ in the stationary growth phase in TY medium and in minimal CSE medium [21]. Furthermore, only under two stress conditions, anaerobic and alkaline stress, the SR5/bsrE RNA ratio fell well below 1, thus allowing toxin expression [21]. Here, we determined SR6/yonT mRNA ratios between 82 and 574 in TY medium and between 9 and 201 in CSE medium without glucose (Figure 3) excluding toxin expression under these conditions. By contrast, in CSE medium with glucose, this value fell already at late logarithmic phase below 2, indicating that 
yonT might be expressed under these conditions. However, it has to be taken into consideration that yonT has the rare GUG start codon preceded by an extended SD sequence with $11 \mathrm{bp}$ complementarity to the anti-SD of B. subtilis $16 \mathrm{~S}$ rRNA, which would efficiently recruit, but slowly release ribosomes [28], thus drastically reducing the probability of toxin synthesis [20].

A hallmark of all TA systems is a stable toxin regulated by an unstable antitoxin. This was confirmed by half-life measurements in several type I TA systems that revealed short half-lives for the regulatory RNA antitoxin and long half-lives for toxin mRNAs (rev. in [4]). In hok/Sok, the hok mRNA is extremely stable with a half-life of about $30 \mathrm{~min}$, whereas antitoxin Sok is short-lived with a half-life of $1 \mathrm{~min}$. Similarly, $b s r G$ mRNA and $b s r E$ mRNA have a half-life of $16 \mathrm{~min}$ and 80-120 min, respectively, whereas those of their cognate antitoxins SR4 and SR5 are $3.5 \mathrm{~min}$ and 7-14 $\mathrm{min}[15,21]$. Surprisingly, the half-live of SR6 (both species) is with $>60$ min extremely long, whereas that of yonT mRNA is with $8 \mathrm{~min}$ more than 7 times shorter. As the $\mathrm{p}_{s r 6}$ activity is extremely low (see Figure 4 ), such a long half-life of SR6 might be required to ensure sufficient antitoxin levels. Due to its long half-life, the identification of RNases responsible for SR6 degradation is not feasible. Interestingly, Durand et al. postulated a half-life of $\approx 1.3 \mathrm{~min}$ for the yonT RNA in the presence of SR6 and a half-life of SR6 of $>20$ min [11]. However, they used another B. subtilis strain which might differ in the activity of certain RNases. In addition, their yonT RNA signal was barely visible making this half-life determination questionable. A determination of half-lives in the absence of SR6 was not performed by these authors. The second toxin RNA regulated by SR6, yoyJ-mRNA, is with a half-life of $>90 \mathrm{~min}$ also very stable (Figure 6). Such a long half-life is rather typical for a toxin mRNA. In addition, in TY medium, but not in CSE or CSEG, two SR6 species exist, one with the expected length of about $100 \mathrm{nt}$, and a longer species of $\approx 215 \mathrm{nt}$ (see Figure 1) that resulted from read-through of the apparently inefficient transcription terminator. The latter species was only detectable at transition phase. Currently, it is unclear which factors allow read-through from $\mathrm{p}_{\text {sr }}$ only in TY medium and during a short time-frame.

\section{3. yonT/SR6 Is a Multistress-Responsive TA System}

Toxin expression has to be tightly controlled: For PSK systems like hok/Sok and fst/RNAII, constitutive expression of both toxin and antitoxin promoters are required (rev. in [4]). The same seems to be true for chromosome-encoded $\operatorname{txp} A /$ RatA [10]. By contrast, B. subtilis bsrG and bsrE are temperature-sensitive [15,21]: $b s r G$ mRNA has a 3- to 4-fold shorter half-life at high temperatures due to refolding at heat-shock which allows RNases $\mathrm{Y}$ and J1 to access newly formed single-stranded regions [27]. Furthermore, for the $b s r E / S R 5$ system, multiple stress conditions affected toxin and/or antitoxin expression, the most pronounced among them were anaerobic and alkaline stress that decreased the antitoxin/toxin RNA ratio 8- to 10-fold and 4- to 5-fold, respectively, as well as ethanol stress, which caused a rapid degradation of toxin RNA by RNase $Y$ within $0.5 \mathrm{~min}$ [21]. E. coli toxin tisB, symE and $\operatorname{din} Q$ promoters are preceded by LexA boxes which make them SOS inducible whereas their antitoxins are expressed constitutively (rev. in $[13,16])$. In the case of SymE, an additional post-translational regulation by Lon protease was reported [16]. S. aureus sprA1 expression decreases two-fold at lower $\mathrm{pH}$, while it increases three-fold under oxidative stress [29]. Interestingly, E. coli ralR is higher expressed in later stages of biofilm development [30]. Likewise, chromosome-encoded type II TA systems as relBE or mazEF were discovered to be sensitive to nutritional stress during growth (rev. in [4]).

Here, we report the effects of several stress factors on yonT mRNA and SR6 (see Figure 7). As in the case of $b s r E$ mRNA, the strongest effect was found for ethanol: within 0.5 min after ethanol addition, yonT mRNA disappeared completely. In contrast to bsrE/SR5, oxygen deficiency did not have significant effects. However, the cell-wall toxin vancomycin, that did neither impact $b s r E$ RNA nor SR5, resulted in a four- and five-fold decrease of yonT RNA and SR6, respectively. This would, however, not alter the SR6/yonT ratio making toxin expression under cell-wall stress unlikely. Interestingly, oxidative stress and iron limitation which resulted in about 2-fold effects on yonT RNA and SR6, were the only stress conditions dependent on sigB. In the case of $b s r E / S R 5$, iron limitation increased the 
amount of antitoxin SR5, also sigB dependent, but oxidative stress had no effect. However, neither in bsrE/SR5 nor yonT/SR6 an additional sigB promoter could be detected, so that SigB dependency is most likely due to other factors controlled by this alternative sigma factor. Manganese stress had no effect on bsrE/SR5, but affected yonT/SR6 significantly, and salt stress had a small impact on yonT/SR6 while it exerted no effect on $b s r E / S R 5$. Surprisingly, temperature shock had the reverse effect on yonT/SR6 compared to $b s r E / S R 5$ or $b s r G / S R 4[15,21]$ : It caused a four-fold increase in the amount of yonT mRNA whereas that of SR6 was reduced four-fold after $60 \mathrm{~min}$. By contrast, bsr $\mathrm{G}$ and $b s r E$ mRNA amounts decreased 10-fold after heat-shock while the amounts of both antitoxins remained constant. Based on these observations, it can be assumed that the toxin YonT might be synthesized upon heat shock. Since secondary structures of yonT RNA or SR6 have not been mapped so far, we currently cannot provide a mechanistic explanation for the heat-shock effects on the amounts of SR6 and yonT RNA.

In summary, we can conclude that yonT/SR6 is also a multistress-responsive type I TA system, and that most probably yonT is expressed upon heat-shock conditions at least in individual cells of the culture.

Future investigations will focus on the elucidation of the mechanisms responsible for the stress effects and on the cellular targets of the two toxins, YonT and YoyJ.

\section{Materials and Methods}

\subsection{Enzymes and DNA Manipulations}

Taq DNA polymerase (Roche), Firepol polymerase (Solis Biodyne), sequenase and Thermoscript reverse transcriptase (Thermoscientific), as well as T7 polymerase and polynucleotide kinase (New England Biolabs) were used. DNA manipulations like plasmid purification, E. coli and B. subtilis transformation were carried out as described [31].

\subsection{Strains, Media and Isolation of Chromosomal DNA}

E. coli strain DH5 $\alpha$ and B. subtilis strains DB104 and 1A100 $(\Delta \mathrm{SP} \beta)$ were used (see Table 1$)$. $1 \mathrm{~A} 100$ was included as this strain does not carry the yonT/sr6 region encoded on the SP $\beta$ prophage. TY served as complex medium for E. coli and B. subtilis and CSE as minimal medium for B. subtilis [32]. Chromosomal DNA from B. subtilis strains was isolated as described [33].

Table 1. Bacterial strains.

\begin{tabular}{|c|c|c|}
\hline Strain & Genotype & Reference \\
\hline E. coli $\mathrm{DH} 5 \alpha$ & $\begin{array}{c}\text { fhu2, } \Delta(\operatorname{argF-lacZ),~U169,phoA,} \\
\text { glnV44, } \$ 80, \Delta(\text { lacZ)M15, } \\
\text { gyrA96, recA1, relA1, endA1, thi-1, } \\
\text { hsdR17 }\end{array}$ & {$[34]$} \\
\hline B. subtilis DB104 & His, nprR, 2 nprE18, $\triangle a p r A 3$ & [35] \\
\hline B. subtilis $1 \mathrm{~A} 100$ & $168 \triangle S P \beta, \operatorname{trp} C 2$ & Ohio strain collection \\
\hline
\end{tabular}

\subsection{Primer Extension}

Primer extension experiments were carried out as described [33] using total RNA from B. subtilis strain DB104 and 5'-labelled primer SB2646 for yonT RNA, SB2648 for SR6 and SB2647 for yonU RNA (primers are listed in Table S2).

\subsection{Vector Construction}

For the determination of promoter activities, transcriptional lacZ fusion plasmids were constructed as follows: A PCR was performed on chromosomal DNA of B. subtilis DB104 with primer pairs 
SB2598/2599 (pMGCR1/5), SB2628/2599 (plasmid pMGCR6), SB2630/2644 (pMGCR8), SB2600/SB264 (pMGCR14) and SB2630/SB2706 (pMGCR16). All primers are listed in Table S2, and all plasmids in Table 2. The resulting fragments were cleaved with BamHI and EcoRI-except pMGCR1/5 that was cleaved with BgIII and BamHI-and inserted into the pMG16 vector digested with the same enzyme pair. Plasmids pMGCR1/5 and pMGCR6 contain $p_{y o n}$ from -500 and -100 , respectively, to +10 with regard to the transcriptional start site (TSS) fused to the promoterless lacZ gene, whereas pMGCR14 comprises $\mathrm{p}_{\text {sr } 6}$ with -500 to +50 and pMGCR8 and pMGCR16 $\mathrm{p}_{\text {sr6 }}$ with -240 to +50 , respectively. Translational yonT-lacZ (pGAY1) and yoyJ-lacZ (pGAY2) fusions were constructed using a PCR with primer pairs SB2760/2761 (pGAY1) or SB2764/SB2765 (pGAY2), respectively on chromosomal DNA. The resulting fragments were digested with BamHI and EcoRI and inserted into the BamH/EcoRI pGAB1 vector. In all cases, the native promoter was replaced by the strong constitutive heterologous promoter pIII [25].

To overexpress sr6, yoyJ and yonU in Bacillus subtilis, plasmids pUCBas, pUCBYJ and pUCBYU were constructed, respectively, as follows: PCR fragments were obtained on chromosomal DNA from B. subtilis strain DB104 with primer pairs SB2654/2655 (pUCBas), SB2690/2691 (pUCBYJ) or SB2635/SB2636 (pUCBYU), cleaved with BamHI and HindIII and inserted into the BamHI/HindIII vector of pUCB2. The cognate $\mathrm{p}_{\text {sr } 6}$ and $\mathrm{p}_{y o n} \mathrm{u}$ promoters and, in case of pUCBYJ, $\mathrm{p}_{y o n T}$, were used. Primer SB2636 contains the heterologous bsrF terminator at its $3^{\prime}$ end [36]. pANC213cat is a vector for integration into the alkaline phosphatase gene (aprE gene) that comprises the tightly controlled IPTG-inducible PSPAC promoter. A promoterless yonT fragment generated on chromosomal DNA as template with primer pair SB2660/SB2661 was cleaved with BamHI and EcoRI and inserted into the BamHI/EcoRI pANC213cat vector. In the resulting plasmid pAPYT3, the yonT start codon was replaced by a stop codon and the $b s r F$ terminator added at the $3^{\prime}$ end. A promoterless yoyJ fragment was produced by PCR on genomic DNA with primer pair SB2722/SB2723, digested with SphI and HindIII and cloned into the SphI/HindIII pDR111 [37] vector that contains the IPTG-inducible hyperspank promoter and can be integrated into the B. subtilis amyE locus.

Table 2. Plasmids used in this study.

\begin{tabular}{|c|c|c|}
\hline Plasmid & Description & Reference \\
\hline pUCB2 & Shuttle vector of pUC19 and pUB110, $\mathrm{Neo}^{\mathrm{R}}, \mathrm{Phleo}^{\mathrm{R}}$ & [38] \\
\hline pDR111 & $\begin{array}{l}\text { Vector for IPTG-inducible overexpression and integration into } \\
\text { the B. subtilis amyE locus, } \text { Spec }^{\mathrm{R}}\end{array}$ & [37] \\
\hline pAPNC213cat & $\begin{array}{l}\text { Vector for IPTG-inducible overexpression and integration into } \\
\text { the B. subtilis } A P \text { locus, } \mathrm{Cm}^{\mathrm{R}}\end{array}$ & {$[24]$} \\
\hline pMG16 & $\begin{array}{l}\text { Vector for integration of transcriptional lacZ fusions into } B \text {. } \\
\text { subtilis amyE locus, } \operatorname{Spec}^{\mathrm{R}}\end{array}$ & $\begin{array}{l}\text { M. Gimpel, } \\
\text { unpublished }\end{array}$ \\
\hline pGAB1 & $\begin{array}{l}\text { Vector for integration of translational lacZ fusions into B. subtilis } \\
\qquad a m y E \text { locus, } \operatorname{Kan}^{\mathrm{R}}\end{array}$ & $\begin{array}{l}\text { S. Brantl, } \\
\text { unpublished }\end{array}$ \\
\hline pMGCR1 & pMG16 with yon $T$ from -500 to $+10 *$ & This study \\
\hline pMGCR6 & pMG16 with yon $T$ from -100 to $+10 *$ & This study \\
\hline pMGCR8 & pMG16 with sr6 from -240 to $+50 *$ & This study \\
\hline pMGCR14 & pMG16 with sr6 from -500 to $+50 *$ & This study \\
\hline pGAY1 & pGAB1 with yonT gene & This study \\
\hline pGAY2 & pGAB1 with yoyJ gene & This study \\
\hline pUCBas & pUCB2 with sr6 gene & This study \\
\hline pUCBYT & pUCB2 with yonT gene & This study \\
\hline pUCBYJ & pUCB2 with yoyJ gene & This study \\
\hline pUCBYU & pUCB2 with yonU gene & This study \\
\hline pAPYT3 & pAPNC213cat with yonT gene (M1Stop) & This study \\
\hline pDRYJ & pDR111 with yoyJ gene & This study \\
\hline
\end{tabular}




\section{5. $\beta$-Galactosidase Assay}

The transcriptional and translational fusions were integrated into the amyE locus of the B. subtilis DB104 or 1A100 chromosome and $\beta$-galactosidase activities were determined as described [38].

\subsection{Determination of the Intracellular Concentrations of yonT mRNA, yoyJ mRNA and SR6}

The intracellular amounts of the RNAs were determined as described previously [21].

\subsection{Preparation of total RNA, RNA Gel Electrophoresis and Northern Blotting}

Preparation of total RNA, RNA gel electrophoresis on $6 \%$ denaturing polyacrylamide gels, and Northern blotting were carried out as described previously [33]. For the detection of yonT mRNA, yoyJ mRNA, yonU mRNA and SR6, [ $\left.\alpha^{-32} \mathrm{P}\right]$ UTP-labeled riboprobes were used generated with T7 RNA polymerase on PCR-derived DNA fragments as described [39]. RNA half-life determinations were performed according to [40], except that $200 \mu \mathrm{g} / \mathrm{mL}$ rifampicin were used.

\subsection{Stress Conditions}

The following stress conditions were applied (final concentrations are indicated): ethanol stress (4\% ethanol), oxidative stress $\left(10 \mathrm{mM} \mathrm{H}_{2} \mathrm{O}_{2}\right)$, salt stress $(0.5 \mathrm{M} \mathrm{NaCl}), \mathrm{Mn}^{2+}$ stress $(1 \mathrm{mM} \mathrm{MnCl})$, iron depletion (250 $\mu \mathrm{M}$ 2,2-Dipyridyl-N,N-dimethylsemicarbazone = DIP, dissolved in DMSO) and cell wall antibiotic stress (10 and $20 \mu \mathrm{g} / \mathrm{mL}$ vancomycin). For heat shock, cultures were shocked from $37^{\circ} \mathrm{C}$ to $48^{\circ} \mathrm{C}$.

Supplementary Materials: The following are available online at www.mdpi.com/xxx/s1, Figure S1: RT PCR on gapA RNA, Figure S2: Calculation of the amounts of yonT RNA and SR6 using standard curves (shown above) obtained by loading and Northern blotting of defined amounts of in vitro synthesized yonT RNAand SR6 in the range of 0.01 to $5 \mathrm{fmol}$ in parallel onto the gels with RNA samples from cultures grown in TY, CSEG and CSE medium (see Figure 3 in the main body of publication), Table S1: $\beta$-galactosidase-activities of translational yonT-1 lacZ and yoyJ lacZ fusions, Table S2: Oligonucleotides used in this study.

Acknowledgments: We are very grateful to Natalie Jahn (formerly AG Bakteriengenetik, Jena) for her help with the adaptation of the experimental methods to the yonT/SR6 system. Furthermore, we thank Peter Müller (AG Bakteriengenetik, Jena) for the search for yonT/sr6/yoyJ genes in other bacterial species and for critical reading of the manuscript. This work was supported by Deutsche Forschungsgemeinschaft BR1552/10-1 (to S.B.).

Author Contributions: S.B. conceived and designed the experiments, C.R. and C.L. performed the experiments; C.R., C.L. and S.B. analyzed the data; S.B. wrote the paper.

Conflicts of Interest: No potential conflicts of interest were disclosed.

\section{Abbreviations}

The following abbreviations are used in this manuscript: aa, amino acid; nt, nucleotide; bp, base pair; sRNA, small RNA, RBS, ribosome binding site, TA, toxin-antitoxin.

\section{References}

1. Brantl, S. Bacterial type I toxin-antitoxin systems. RNA Biol. 2012, 9, 1488-1490. [CrossRef] [PubMed]

2. Page, R.; Peti, W. Toxin-antitoxin systems in bacterial growth arrest and persistence. Nat. Chem. Biol. 2016, 12, 208-214. [CrossRef] [PubMed]

3. Aakre, C.D.; Phung, T.N.; Huang, D.; Laub, M.T. A bacterial toxin inhibits DNA replication elongation through a direct interaction with the $\beta$ sliding clamp. Mol. Cell 2013, 52, 617-628. [CrossRef] [PubMed]

4. Brantl, S.; Jahn, N. sRNAs in bacterial type I and type III toxin/antitoxin systems. FEMS Microbiol. Rev. 2015, 39, 413-427. [CrossRef] [PubMed]

5. Gerdes, K.; Wagner, E.G.H. RNA antitoxins. Curr. Opin. Microbiol. 2007, 10, 117-124. [CrossRef] [PubMed]

6. Fozo, E.M.; Makarova, K.S.; Shabalina, S.A.; Yutin, N.; Koonin, E.V.; Storz, G. Abundance of type I toxin-antitoxin systems in bacteria: Searches for new candidates and discovery of novel families. Nucleic Acids Res. 2010, 38, 3743-3759. [CrossRef] [PubMed] 
7. Weaver, K.E. The par toxin-antitoxin system from Enterococcus faecalis plasmid pAD1 and its chromosomal homologs. RNA Biol. 2012, 9, 1498-1503. [CrossRef] [PubMed]

8. Weaver, K.E. The type I toxin-antitoxin par locus from Enterococcus faecalis plasmid pAD1: RNA regulation by both cis- and trans-acting elements. Plasmid 2014, 78, 65-70. [CrossRef] [PubMed]

9. Gerdes, K.; Christensen, S.K.; Løbner-Olesen, A. Prokaryotic toxin-antitoxin stress response loci. Nat. Rev. Microbiol. 2005, 3, 371-382. [CrossRef] [PubMed]

10. Silvaggi, J.M.; Perkins, J.B.; Losick, R. Small untranslated RNA antitoxin in Bacillus subtilis. J. Bacteriol. 2005, 187, 6641-6650. [CrossRef] [PubMed]

11. Durand, S.; Gilet, L.; Condon, C. The essential function of B. subtilis RNase III is to silence foreign toxic genes. PLoS Genet. 2012, 8, e1003181. [CrossRef] [PubMed]

12. Arnion, H.; Korkut, D.N.; Masachis Gelo, S.; Chabas, S.; Reignier, J.; Iost, I.; Darfeuille, F. Mechanistic insights into type I toxin antitoxin systems in Helicobacter pylori: The importance of mRNA folding in controlling toxin expression. Nucleic Acids Res. 2017, 45, 4782-4795. [PubMed]

13. Wagner, E.G.H.; Unoson, C. The toxin-antitoxin system tisB-istR1. Expression, regulation and biological role in persister phenotypes. RNA Biol. 2012, 9, 1513-1519. [CrossRef] [PubMed]

14. Fozo, E.M. New type I toxin-antitoxin families from "wild" and laboratory strains of E. coli. Ibs-Sib, ShoB-OhsC and Zor-Orz. RNA Biol. 2012, 9, 1504-1512. [PubMed]

15. Jahn, N.; Preis, H.; Wiedemann, C.; Brantl, S. BsrG/SR4 from Bacillus subtilis-The first temperature-dependent type I toxin-antitoxin system. Mol. Microbiol. 2012, 83, 579-598. [CrossRef] [PubMed]

16. Kawano, M. Divergently overlapping cis-encoded antisense RNA regulating toxin-antitoxin systems from E. coli: Hok/sok, ldr/rdl, symE/symR. RNA Biol. 2012, 9, 1520-1527. [CrossRef] [PubMed]

17. Weel-Sneve, R.; Kristiansen, K.; Odsbu, I.; Dalhus, B.; Booth, J.; Rognes, T.; Skarstad, K.; Bjoras, M. Single transmembrane peptide DinQ modulates membrane-dependent activities. PLoS Genet. 2013, 8, e1003260. [CrossRef] [PubMed]

18. Guo, Y.; Quiroga, C.; Chen, Q.; McAnulty, M.J.; Benedik, M.J.; Wood, T.K.; Wang, X. RalR (a DNase) and RalA (a small RNA) form a type I toxin-antitoxin system in Escherichia coli. Nucleic Acids Res. 2014, 42, 6448-6462. [CrossRef] [PubMed]

19. Berghoff, B.A.; Hoekzema, M.; Aulbach, L.; Wagner, E.G.H. Two regulatory RNA elements affect TisB-dependent depolarization and persister formation. Mol. Microbiol. 2017, 103, 1020-1033. [CrossRef] [PubMed]

20. Durand, S.; Jahn, N.; Condon, C.; Brantl, S. Type I toxin-antitoxin systems in Bacillus subtilis. RNA Biol. 2012, 9, 1491-1497. [CrossRef] [PubMed]

21. Müller, P.; Jahn, N.; Ring, C.; Maiwald, C.; Neubert, R.; Meißner, C.; Brantl, S. A multistress responsive type I toxin-antitoxin system: BsrE/SR5 from the B. subtilis chromosome. RNA Biol. 2016, 13, 511-523. [CrossRef] [PubMed]

22. Meißner, C.; Jahn, N.; Brantl, S. In vitro characterization of the type I toxin-antitoxin system $b s r E / S R 5$ from Bacillus subtilis. J. Biol. Chem. 2016, 291, 560-571. [CrossRef] [PubMed]

23. Jahn, N.; Brantl, S. One antitoxin-two functions: SR4 controls toxin mRNA decay and translation. Nucleic Acids Res. 2013, 41, 9870-9880. [CrossRef] [PubMed]

24. Jahn, N.; Brantl, S.; Strahl, H. Against the mainstream: The membrane associated type I toxin BsrG from Bacillus subtilis interferes with cell envelope biosynthesis without increasing membrane permeability. Mol. Microbiol. 2015, 98, 651-666. [CrossRef] [PubMed]

25. Brantl, S. The $\operatorname{cop} R$ gene product of plasmid pIP501 acts as a transcriptional repressor at the essential repR promoter. Mol. Microbiol. 1994, 14, 473-483. [CrossRef] [PubMed]

26. Brantl, S. Regulatory mechanisms employed by cis-encoded antisense RNAs. Curr. Opin. Microbiol. 2007, 10, 102-109. [CrossRef] [PubMed]

27. Jahn, N.; Brantl, S. Heat shock induced refolding entails rapid degradation of $b s r G$ toxin mRNA by RNases $Y$ and J1. Microbiology 2016, 162, 590-599. [CrossRef] [PubMed]

28. Li, G.W.; Oh, E.; Weissman, J.S. The anti-Shine-Dalgarno sequence drives translational pausing and codon choice in bacteria. Nature 2012, 484, 538-541. [CrossRef] [PubMed]

29. Sayed, N.; Jousselin, A.; Felden, B. A cis-antisense RNA acts in trans in Staphylococcus aureus to control translation of a human cytolytic peptide. Nat. Struct. Mol. Biol. 2011, 19, 105-112. [CrossRef] [PubMed] 
30. Domka, J.; Lee, J.; Bansal, T.; Wood, T.K. Temporal gene-expression in Escherichia coli K-12 biofilms. Environ. Microbiol. 2007, 9, 332-3346. [CrossRef] [PubMed]

31. Brantl, S.; Behnke, D. Characterization of the minimal origin required for replication of the streptococcal plasmid pIP501 in Bacillus subtilis. Mol. Microbiol. 1992, 6, 3501-3510. [CrossRef] [PubMed]

32. Heidrich, N.; Chinali, A.; Gerth, U.; Brantl, S. The small untranslated RNA SR1 from the B. subtilis genome is involved in the regulation of arginine catabolism. Mol. Microbiol. 2006, 62, 520-536. [CrossRef] [PubMed]

33. Licht, A.; Preis, S.; Brantl, S. Implication of CcpN in the regulation of a novel untranslated RNA (SR1) in B. subtilis. Mol. Microbiol. 2005, 58, 189-206. [CrossRef] [PubMed]

34. Hanahan, D. Studies on transformation of Escherichia coli with plasmids. J. Mol. Biol. 1983, 166, 557-580. [CrossRef]

35. Kawamura, F.; Doi, R.H. Construction of a Bacillus subtilis double mutant deficient in extracellular alkaline and neutral proteases. J. Bacteriol. 1984, 160, 442-444. [PubMed]

36. Preis, H.; Eckart, R.A.; Gudipati, R.K.; Brantl, S. CodY activates transcription of a small RNA in Bacillus subtilis. J. Bacteriol. 2009, 191, 5446-5457. [CrossRef] [PubMed]

37. Van Ooij, C.; Losick, R. Subcellular localization of a small sporulation protein in Bacillus subtilis. J. Bacteriol. 2003, 185, 1391-1398. [CrossRef] [PubMed]

38. Gimpel, M.; Heidrich, N.; Mäder, U.; Krügel, H.; Brantl, S. A dual-function sRNA from Bacillus subtilis: SR1 acts as a peptide-encoding mRNA on the gapA operon. Mol. Microbiol. 2010, 76, 990-1009. [CrossRef] [PubMed]

39. Heidrich, N.; Brantl, S. Antisense-RNA mediated transcriptional attenuation: Importance of a U-turn loop structure in the target RNA of plasmid pIP501 for the efficient inhibition by the antisense RNA. J. Mol. Biol. 2003, 333, 917-929. [CrossRef] [PubMed]

40. Brantl, S.; Wagner, E.G.H. An unusually long-lived antisense RNA in plasmid copy number control: In vivo RNAs encoded by the streptococcal plasmid pIP501. J. Mol. Biol. 1996, 255, 275-288. [CrossRef] [PubMed]

(C) 2018 by the authors. Licensee MDPI, Basel, Switzerland. This article is an open access article distributed under the terms and conditions of the Creative Commons Attribution (CC BY) license (http://creativecommons.org/licenses/by/4.0/). 